\title{
Searching under the streetlight?: Age biases in the personal and family relationships literature
}

\author{
KAREN L. FINGERMAN AND ELIZABETH L. HAY \\ The Pennsylvania State University
}

\begin{abstract}
Two studies addressing age biases in research on family and social relationships are presented. Study 1 involved a content analysis of nearly 1,000 empirical studies published in six major journals from 1994 to 1999. Studies in these journals generally were limited to samples of adults under the age of 45, though nearly one third of the studies failed to include information about the ages of adult participants. Most research focused on marital ties, romantic partnerships, or relationships between parents and young children. Study $2(N=186)$ assessed beliefs about the importance of various relationships to adults of different ages. Researchers who study relationships $(n=71)$, adults with advanced degrees in other fields $(n=57)$, and less-educated adults $(n=58)$ rated the importance of various social ties to themselves and to adults of different ages. In general, participants agreed that adults of different ages value different social ties. Less-educated individuals rated many social ties as more important than did researchers who study relationships, however. Age biases in sampling and the types of relationships that receive research attention are discussed.
\end{abstract}

Researchers have established that adults of all ages get a great deal out of their social relationships (Antonucci, 2001); however, it is unclear whether current research encompasses the variety of social ties that are important to adults of different ages. Studies of adult development indicate that social ties change considerably across adulthood; young, middle-aged, and older adults find different types of relationships meaningful (Antonucci \& Akiyama, 1987; Carstensen, 1995; Levitt,

This study was funded by Grant AG1448401, "Adults' Reasoning about Social Problems across Adulthood," from the National Institutes on Aging awarded to the first author. This paper was written while the second author was supported by a grant from Pennsylvania State University for graduate studies and a National Science Foundation Graduate Fellowship. Portions of this paper were presented in the "Under-researched topics in social support" symposium, K. L. Fingerman (chair), at the Gerontological Society of America annual meeting, 1999. We are grateful to Beth VanCitters for help with this project. Jennifer Lansford provided invaluable comments on a draft of this paper.

Address correspondence to the first author at the Department of Human Development and Family Studies, Pennsylvania State University, 110 Henderson Bldg. South, University Park, PA 16802; e-mail: kxf18@psu.edu.
Weber, \& Guacci, 1993). Yet, a cursory review of the literature addressing social relationships suggests most studies focus on younger adults, without considering age differences in adults' social worlds. This paper systematically examines the extent to which studies in the family and personal relationships journals include adults of different ages. Here, the term researcher refers to scholars who have authored empirical studies published in family and personal relationships journals and research literature refers to those publications.

We focus on three questions about possible biases in the research literature. First, are adults of all ages represented in studies of social relationships? Second, are there age biases in the types of relationships examined in the literature? In other words, does the literature encompass the range of social ties adults of different ages consider important, or focus on a subset of ties of interest to a particular age group? Third, do observed biases reflect relationship scholars' personal beliefs about the importance of different social ties?

With regard to these research questions, one hypothesis is that researchers have examined 
age groups and social ties that are easy to investigate, while ignoring other important relationships in adults' social worlds. Metaphorically, relationship scholars may be committing the error of the person who lost car keys at the far end of the street, but searched under the streetlight because it was convenient. Alternatively, relationship scholars may research particular age groups and social ties because they believe these ties are the most important relationships to examine. Two studies address these issues. In Study 1, we examined age and relationship biases in recent empirical research published in family and relationships journals. To explore the reason for these biases, in Study 2, we examined relationship scholars' beliefs about the importance of relationships at various ages.

\section{Age as a variable in the social world}

The first research question focuses on age biases in the research literature. We expected to find a disproportionate number of studies sampling younger adults, to the exclusion of older adults. This expectation is based on several observations. College student samples appear to pervade the relationship literature (e.g., Agnew, Van Lange, Rusbult, \& Langston, 1998; Gurung, Sarason, \& Sarason, 1997). Young adults are more willing to respond to forced-choice survey questions that social scientists use most often in their research, whereas older adults prefer to respond to openended questions, which require coding, time, and labor (Fingerman, 2001; Ingersoll-Dayton \& Talbott, 1992; Morgan, 1989). Health problems accumulate throughout adulthood (National-Center for Health Statistics, 2001). Young adults tend to have fewer health problems and may be more available to participate in studies of social ties than older adults who may be ill. In sum, it is easier to implement a study of young adults' social lives than of older adults' social lives.

Given that adults of different ages appear to value or to have different types of relationships, over-sampling of younger adults may also be associated with biases in the types of relationships that receive research attention. Adults of different ages live in different social contexts. Young adults are likely to be establishing careers, finding partners, and having children; they are also likely to have living parents. Older adults are unlikely to have living parents, are likely to be retired and widowed, but they also may have more children and grandchildren than their younger counterparts (Fingerman \& Birditt, in press). In general, older adults have smaller social networks than do younger adults, but older adults' networks have proportionally more family members than younger adults' networks (Antonucci, 2001; Carstensen, 1995; Levitt et al., 1993). The research literature on the whole, however, may not reflect these age differences. Therefore, in addition to considering biases in the ages of sample participants, we considered biases in the types of relationships researchers have examined.

\section{Familial, friendship, and peripheral social ties}

The history of family research is fraught with biases concerning the priority of different types of social ties. During the World War II era, social scientists argued that the childrearing family was the primary unit of social organization (Doherty, Boss, LaRossa, Schumm, \& Steinmetz, 1993; Parsons, 1949, 1960), and married, two-parent families with children became the central unit of investigation (Widmer, 1999). Research on romantic relationships that might lead to marriage blossomed as well. This focus on childrearing and romantic ties involves age biases. Gerontologists note that older adults have a broader conception of family than do younger adults. Young adults tend to value their partners and young children as their family, whereas older adults include their spouse, siblings, in-laws, grown children, and grandchildren as family (Bedford \& Blieszner, 1997; Fingerman, 2001; Fingerman \& Bermann, 2000; Troll, 1996). We expected the relationship literature to emphasize romantic ties and the childrearing family (e.g., spouse and young children) valued by younger adults, with other kinship ties receiving less attention.

We also expected to find a neglect of non-kin relationships, despite their importance to adults of different ages. For example, adults of all ages 
value their friendships (Blieszner \& Adams, 1992), but friendships do not appear to be a dominant topic in the research literature. Several major journals focus on family ties, but there is no major journal focusing on friendship.

Although family ties are clearly important in individuals' lives, less intimate relationships may serve distinct functions as well. Elsewhere, we have labeled such relationships peripheral ties, and noted their omission from the research literature (Fingerman, in press; Fingerman \& Griffiths, 1999). For example, church members and neighbors may be important to many older adults (Cantor, 1979; Johnson \& Barer, 1997; Krause, $1995)$, yet these social ties are rarely studied. Researchers confront difficulties conducting empirical studies of these ties. For example, which church members would be included in a study? Which church members would be the target of the study and would define the importance of these social ties? By contrast, the marital relationship can be accessed through public records with consensus over the parameters of the tie. In sum, childrearing families provide a tidy research design, whereas peripheral ties do not.

The types of peripheral ties that do receive research attention may also reflect age biases in the literature. Young adults may be invested in peripheral ties they hope will become closer in the future. Older adults appear less interested in peripheral ties in general than younger adults (Carstensen, 1995), but may hold on to a few such ties that allow them to reminisce about the past or that currently provide support (Fingerman \& Griffiths, 1999). In sum, we expected to find few studies of friendships or peripheral ties. Further, we expected the scant research on these topics to involve younger adults rather than older adults.

\section{Other biases in the research literature}

Biases in the relationships literature are pervasive. Theorists have pointed out that research on social relationships has failed to include ties of importance to ethnic minority, female, or gay and lesbian adults (Adams, 1988; Blieszner \& Adams, 1992; Gaines, 1995;
McGoldrick, 1993; Wood \& Duck, 1995). For example, research on African American families indicates that female lineage ties (e.g, grandmother/mother/daughter) may be more central than marital ties in many families (Franklin, 1997; Spitze \& Miner, 1992; Sudarkasa, 1997; Taylor, Jackson, \& Chatters, 1997). Specific Latino groups place a strong emphasis on extended family ties (Becerra, 1988; Leyendecker \& Lamb, 1999; SanchezAyendez, 1988). Although we recognize these other biases, here we focus specifically on the issue of ageism in the literature pertaining to adults' social ties.

In Study 1, we examined whether age biases exist in the relationship and family literature. A content analysis focused on the ages of sample participants and the types of relationships examined in recent empirical articles published in six major relationship journals. Study 2 addressed a possible explanation for biases revealed in Study 1. We examined differences in beliefs about the importance of specific relationships to adults of different ages. Relationship scholars, individuals with advanced degrees in other fields, and less-educated individuals rated the importance of familial, friendship, and peripheral ties to themselves personally, and to adults of different ages.

\section{Study 1: Content Analysis of Empirical Studies Pertaining to Social Relationships}

Study 1 examined empirical research on personal relationships published in the 1990s. We expected that (a) the majority of studies would include younger adults to the exclusion of older adults, (b) romantic, spousal, and childrearing relationships would receive more attention than the wider array of family ties of importance to older adults, and (c) friendship and peripheral ties would receive scant attention, and then, only with regard to younger adults.

\section{Study 1 Methods}

This study examined empirical research addressing adults' relationships published in peer-reviewed journals from 1994 to 1999. 
Because it is not possible to analyze the complete literature on relationships, we focused on a subset of publications issued during that period.

\section{Selection of journals and articles for consideration}

Empirical research addressing adults' social relationships is published primarily in three types of journals: family and relationships journals (e.g., Personal Relationships, Journal of Marriage and the Family), developmental and gerontological journals (e.g., Developmental Psychology, Psychology and Aging), and specialty journals (e.g., Divorce and Remarriage). In selecting journals for this study, we used three criteria: (a) an emphasis on relationship research, (b) high circulation (e.g., the membership of a research society concerned with relationships), and (c) high citation rates. We ruled out the developmental and gerontological journals based on our first criterion, emphasis on relationships. On average, fewer than two articles per issue in those journals focused on adults' relationships. ${ }^{1}$ Next, we used the impact index and total citation index of the Social Science Citation Index to examine citation rates of papers published in the family, relationships, and specialty journals. The impact index estimates citation rates as a function of the number of papers published in a given journal during a two-year period; the total citation index reflects the overall number of citations in a given year. We excluded the specialty journals based on low circulation and citation rates.

We selected three journals focusing on family relationships and three journals focusing on personal relationships that fit the criteria (see Table 1). These journals have high circulation rates and are widely cited in other publications. For example, the impact index for the Journal of Family Psychology was 1.22 for 1995 to 1996, compared to an impact index of 0.13 for Journal of Divorce and Remarriage.

1. Child Development and Developmental Psychology do publish studies on parent/child ties at a high rate. These studies focus on the children however, rather than on the adults.
The Journal of Personality and Social Psychology does not focus on relationship research; however, we included this journal because of its high citation rates and the impact that studies of relationships published in this journal might have on scholars. Although the selected journals do not represent the full literature on family and personal relationships, studies published in these journals are likely to influence future research.

We limited Study 1 to empirical studies examining relationships in adulthood. Literature reviews, theoretical papers, meta-analyses, book reviews, commentaries, and editorials were excluded. Studies with sample participants under the age of 18 were also excluded. The selected journals publish studies on a wide array of topics including social status, personality, attitudes, and well-being. We excluded studies on such topics as the economic status of divorced women, in-group/out-group distinctions, coping with stress, and attitudes toward intimacy. The distribution of papers included and excluded from each journal is found in Table 1. Because 66 articles included multiple studies, the total number of studies $(N=976)$ is greater than the total number of articles.

To ensure that we had not introduced age biases into our sample of the literature by selecting only those studies addressing relationships, we also randomly selected 100 studies published in the same journals from 1994 to 1999 that did not meet our study criteria. A content analysis revealed the age distribution of sample participants in these studies did not differ from the studies we considered here.

\section{Content analysis of age of sample and relationships}

To ascertain the frequency with which different age groups appear in the literature, we conducted a content analysis of each study. Independent coders used information in the articles to determine whether the sample included adults in the following age groupings: 18 to 29 years, 30 to 44 years, 45 to 59 years, 60 to 79 years, and 80 years plus. Dichotomous codes were used, 1 = sample fits age category, 0 = sample does not fit age category. If a study included a wide age range 
Table 1. Number of studies from each journal included in Study 1

\begin{tabular}{lcr}
\hline \hline Journal & Studies included & Papers excluded \\
\hline Relationships journals & & \\
Personal Relationships & 124 & 71 \\
Journal of Social and Personal Relationships & 177 & 143 \\
Journal of Personality and Social Psychology & 118 & 1064 \\
& & \\
Family journals & & 405 \\
Journal of Marriage and the Family & 315 & 112 \\
Journal of Family Issues & 101 & 119 \\
Journal of Family Psychology & 141 & \\
\hline \hline
\end{tabular}

of adults (e.g., adults aged 20 to 60), raters coded a 1 for each age group covered.

About half of the studies $(n=454)$ included a mean and information about the distribution of age (e.g., standard deviation, range), permitting us to code the full age range of the sample. Other studies provided only mean age of the sample $(n=190)$. We coded these studies in the age group for that mean. The remaining studies either did not include information about ages of participants $(n=246)$ or indicated only that the sample consisted of college students $(n=86)$. When researchers did not include information about age, they tended to define the sample around a specific role, such as parents of second graders (and supplied information about age for the children). When researchers indicated only that the sample participants consisted of college students, we interpolated the age range. Studies of college students that reported age $(n=153)$ consistently involved individuals aged 18 to 29 years; we placed studies of college students that did not provide age $(n=86)$ in that category. Studies for which ages of the participants could not be ascertained were excluded from analyses involving the distribution of age.

Raters then coded the relationships investigated in each study. We attempted to classify the studies based on the participants' relationships. For example, if a study examined adults' feelings about their children under age 18, the relationship was coded as "young child." Studies that examined caregivers of a spouse or parent were included under "spouse" or "parent." A few studies of unspecified care- giver relationships were coded as "caregiving ties." Studies focusing on the family in general were coded as "unspecified family members." Studies classified as social supportive ties tended to include unspecified family members and friends. Interrater reliability for coding was better than $90 \%$ agreement; disagreements were resolved through consultation.

Two hundred and thirty-four studies examined multiple age groups (e.g., participants aged 18 to 60 years) and 380 studies examined multiple relationships (e.g., spouse, child, and friend). We coded such studies under more than one age group or relationship (rather than attempting to control for nonindependence of records) to most accurately represent the age groups and topics currently found in the literature. Therefore, in addition to considering the number of studies $(N=976)$, in some analyses we also considered the number of "hits" (a "hit" being the number of times coders assigned a " 1 " to indicate that the sample fit an age group or the study fit a relationship category). Because several studies encompassed multiple age groups, the total number of "hits" for age was 1,140. Likewise, when we examined type of relationship (e.g., child, spouse, friend) by age group, the total number of "hits" was 2,319. Yet no single study accounted for a disproportionate number of "hits." More than $96 \%$ of studies looked at four or fewer relationships; $94 \%$ looked at three or fewer age groups, and the largest study had 35 total hits. Below, we indicate when we used the total number of studies $(N=976)$ and when we used "hits" as our unit of analysis. 


\section{Results of Study 1}

Because we used dichotomous codes regarding whether a study included each age group (ages 18 to 29 years, 30 to 44 years, etc.) and each relationship category (child, spouse, friend), our analysis strategy relied on chisquare tests. Furthermore, analyses were estimated twice, once pooling across journals and once within each journal. We adjusted the significance level to $p<.01$ to take into account multiple analyses. Except where noted, the pattern of findings was identical across journals and within individual journals.

\section{Distribution of age}

The first research question asks whether young adults are overrepresented in the research literature relative to other age groups. We examined this question in two ways. First, we compared the distribution of age in the studies to the distribution of age in the adult population of the United States. Then, we looked at the distribution of age groups studied to ascertain whether certain age groups are researched at a disproportionately higher rate than other age groups.

Figure 1 provides a comparison of studies in the journals examining adults of different ages with the distribution of each age group in the U.S. population (U.S. Census Bureau, 2000). To compare age in the literature and the population, we used the total number of coded "hits" for age $(n=1,140)$. Thus, the proportions of age groups in the research literature and the proportions of adults in the population data sum to 1.00 , permitting clearer comparisons. As can be seen, studies in the literature include younger adults at higher rates than their proportion in the population, and include older adults at lower rates than their proportion in the population.

Next, we examined the probability that a given study included a specific age group. In these analyses, we were interested in the likelihood that a scholar who reads a study examining relationships in these six journals gains information about young adults, middleaged adults, or older adults. We considered the distribution of age groups as a percentage of studies published in the six journals $(N=976)$. Because some studies included more than one age group, percentages do not sum to 100 . With this approach, the age distribution was even more distorted. Younger adults appeared in $50 \%$ of studies, adults aged 30 to 44 years appeared in $36 \%$ of studies, adults aged 45 to 59 appeared in $18 \%$ of studies, adults aged 60 to 79 appeared in $10 \%$ of studies, and adults over the age of 80 appeared in only $3 \%$ of studies. In

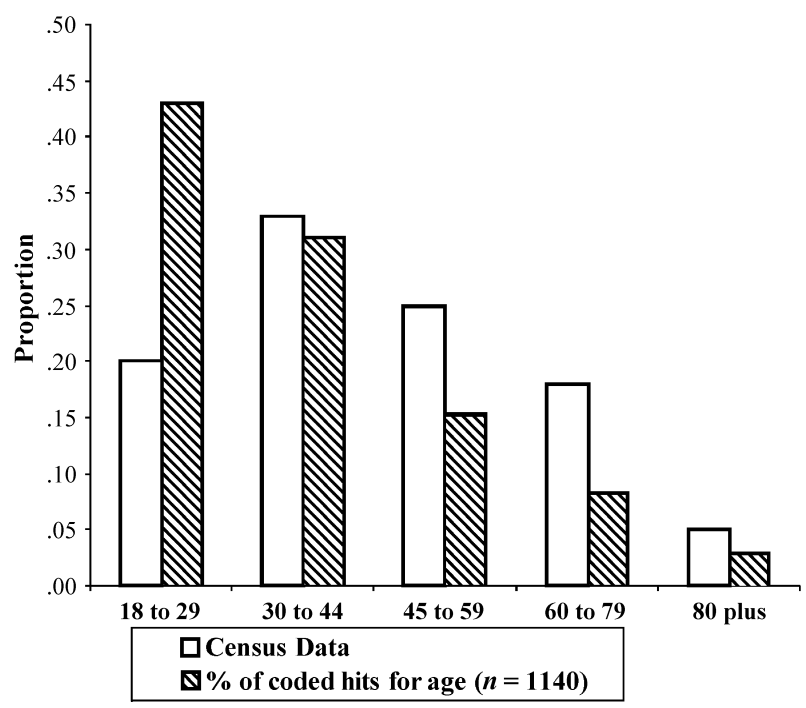

Figure 1. Age distribution found in the research literature and in the U.S. population. 
other words, studies that examined older adults' relationships tended to include younger adults as well, but the reverse was not true.

A chi-square test comparing the proportions of studies including each of the five age groups provides further evidence of an inequitable distribution of age across studies $\left(\chi^{2}=632.48, d f=4, p<.01\right)$. We then estimated $2 \times 2$ chi-square tests comparing each age group to every other age group (these analyses are not shown here but all were significant at $p<.01$ ). Adults aged 18 to 29 years appeared in the most studies, and older age groups received progressively less attention. Family journals differed slightly from this pattern by including adults aged 30 to 44 years as often as they included adults aged 18 to 29 . Few studies in any of these journals included adults over the age of 45 .

\section{Distribution of types of relationships}

The second research question asked whether certain types of relationships appear more often in the literature than do other types of relationships. The proportion of studies examining each type of relationship, rank-ordered by appearance in the literature, is found in Table 2. Proportions are presented to three decimal places because some relationships appeared in only one or two studies. As expected, more studies investigated spouses, romantic partners, and young children than other types of relationships. Parents of adult offspring received some attention, as did friendships. The remaining relationship types appeared in fewer than $10 \%$ of studies.

To clarify whether the types of relationships that receive research attention are associated with age biases, we then considered the types of relationships studied in samples of different ages. Our initial predictions indicated that studies would focus on relationships of interest to young adults (spouse, romantic partner, young children). It is possible, however, that the few studies including older adults focus on relationships of interest to this age range, such as spouse, grown child, grandchildren, inlaws, or neighbors.

Table 3 shows the five relationships most frequently investigated in studies with samples
Table 2. Proportion of studies examining each type of relationship

\begin{tabular}{|c|c|}
\hline Relationship & $\begin{array}{c}\text { Studies } \\
(N=976)\end{array}$ \\
\hline Spouse & .443 \\
\hline Young child & .256 \\
\hline Romantic ties & .252 \\
\hline Parents & .166 \\
\hline Friend & .127 \\
\hline Unspecified family relationships & .079 \\
\hline Adult child & .075 \\
\hline Stepchild & .043 \\
\hline Sibling & .041 \\
\hline $\begin{array}{l}\text { Unspecified supportive } \\
\text { relationships }\end{array}$ & .031 \\
\hline Lesbian/Gay partner & .017 \\
\hline Acquaintance & .015 \\
\hline Grandparent & .015 \\
\hline Best Friend & .012 \\
\hline Coworker & .011 \\
\hline Schoolmate & .011 \\
\hline Grandchild & .010 \\
\hline Mother/Father-in-law & .009 \\
\hline Ex-spouse & .007 \\
\hline Ex-boy/Ex-girlfriend & .007 \\
\hline Neighbor & .007 \\
\hline Caregiving ties & .006 \\
\hline Boss & .006 \\
\hline Stepparent & .005 \\
\hline Son/Daughter-in-law & .004 \\
\hline Self-help group members & .004 \\
\hline Teacher & .003 \\
\hline Church member & .002 \\
\hline Connections through children & .002 \\
\hline Doctor/Nurse & .002 \\
\hline Foster family & .002 \\
\hline Roommate & .002 \\
\hline Aunt/Uncle & .001 \\
\hline Brother/Sister-in-law & .001 \\
\hline Clergy & .001 \\
\hline Club member & .001 \\
\hline Community member & .001 \\
\hline Cousin & .001 \\
\hline Great grandchild & .001 \\
\hline
\end{tabular}


Table 3. Most frequently examined relationships in each age group and their proportions in the studies $(N=976)$

\begin{tabular}{|c|c|c|c|c|c|c|c|c|c|c|c|}
\hline \multirow{2}{*}{\multicolumn{2}{|c|}{$\begin{array}{l}\text { Aged } \\
18 \text { to } 29 \\
\text { Romantic } .20\end{array}$}} & \multicolumn{2}{|c|}{$\begin{array}{c}\text { Aged } \\
30 \text { to } 44\end{array}$} & \multicolumn{2}{|c|}{$\begin{array}{c}\text { Aged } \\
45 \text { to } 59\end{array}$} & \multicolumn{2}{|c|}{$\begin{array}{l}\text { Aged } \\
60 \text { to } 79\end{array}$} & \multicolumn{2}{|c|}{$\begin{array}{l}\text { Aged } \\
80 \text { plus }\end{array}$} & \multicolumn{2}{|c|}{$\begin{array}{l}\text { Aged not } \\
\text { provided }\end{array}$} \\
\hline & & Spouse & .23 & Spouse & .11 & Spouse & .06 & Adult ch & .01 & Spouse & .11 \\
\hline Spouse & .18 & $\begin{array}{l}\text { Young } \\
\text { child }\end{array}$ & .11 & $\begin{array}{l}\text { Young } \\
\text { child }\end{array}$ & .04 & $\begin{array}{l}\text { Adult } \\
\text { child }\end{array}$ & .02 & Spouse & .01 & $\begin{array}{l}\text { Young } \\
\text { child }\end{array}$ & \\
\hline Friend & .09 & Romantic & .05 & Romantic & .03 & Romantic & .02 & Family $^{\mathrm{a}}$ & .01 & Parents & .06 \\
\hline Parents & .08 & Parents & .04 & Parents & .02 & Friend & .01 & - & & Romantic & .03 \\
\hline $\begin{array}{l}\text { Young } \\
\text { child }\end{array}$ & .07 & Family $^{\mathrm{a}}$ & .03 & $\begin{array}{l}\text { Adult } \\
\text { child }\end{array}$ & .02 & Family $^{\mathrm{a}}$ & .01 & - & & $\begin{array}{l}\text { Adult } \\
\text { child }\end{array}$ & .03 \\
\hline
\end{tabular}

Note. Other relationships are studied less frequently in each age group.

${ }^{a}$ Family members, relationships not specified

of each age group (other relationships, such as siblings, appeared at even lower rates in these journals). Again, we were interested in whether studies in these journals examined specific relationships in each age group; therefore, we used the number of studies $(N=976)$ as the unit of analysis. So few studies included adults over the age of 80 that it is difficult to draw conclusions about the types of relationships examined in this age range. As can be seen, spouse and romantic ties were the most commonly investigated relationships in the other age groups. Children, regardless of their ages, were widely examined. Finally, most studies that did not report ages of the sample group focused on childrearing ties (spouse, children under age 18), suggesting that age biases involving young adult samples may be greater than available information indicates.

To systematically examine whether certain relationships receive more attention than other relationships within each age group, we estimated chi-square tests as follows. We used the rank-ordered list for the appearance of relationships in studies of each age group in Table 3. We then estimated a chi-square test to see if the most frequently researched relationship received more attention than the second most frequently ranked relationship. If that test was significant, we knew the most frequently researched relationship would differ from all other relationship types. If it was not significant, we continued testing until we found a significant difference. Relationships other than the top five relationships listed in Table 3 received so little attention that tests were not performed to differentiate among those ties. Given the small number of studies including adults over the age of 80 , analyses could not be estimated for this age group.

Among adults aged 18 to 29 years, spousal and romantic ties received similar research attention. Friendships received significantly less attention than spousal ties $\left(\chi^{2}=26.9\right.$, $p<.01)$. Friendships, ties with parents, and ties to young children received similar attention for the 18- to 29-year-olds sampled. For adults aged 30 to 44 , the spousal tie received more attention than ties to young children $\left(\chi^{2}=38.12, p<.01\right)$. Ties to young children, in turn, received more attention than romantic ties $\left(\chi^{2}=22.2, p<.01\right)$. The remaining relationships received similar attention for this age range. For adults aged 45 to 59 years and adults aged 60 to 79 , spousal ties received more attention than ties to children $\left(\chi^{2}=31.67\right.$, $p<.01$ and $\chi^{2}=17.78, p<.01$, respectively). Other relationships did not differ for this age range. In sum, regardless of the age of sample, most research attention focused on romantic partner or spouse.

Our initial predictions also involved differences in the types of peripheral ties that receive attention with samples of different ages. Only 54 studies examined peripheral ties; therefore we could not estimate chi-square tests of these ties in samples of different ages. Most studies 
of peripheral ties also involved young adults; only 17 of these studies included adults over the age of 45 years.

\section{Study 1 Discussion}

Content analysis of articles pertaining to family and personal relationships revealed the following biases. First, many studies included younger adults and few studies included older adults in the samples. Second, many studies failed to report the ages of adults in their samples. Third, the relationships examined in the most studies tend to be of importance to young adults, whereas some relationships that older adults may value (e.g., grandchildren) rarely appeared in this literature.

The ages of samples may be associated with issues of convenience, particularly the large proportion of studies relying on college students. Studies in family journals did include adults ages 30 to 44 years, but few studies overall included adults over the age of 45 .

The use of samples including younger adults was associated with the types of relationships examined. Many studies focused on romantic ties, spouses, and children under the age of 18 . Intergenerational ties involving adult offspring and parents received some attention, as did friendships, but these relationships were represented in fewer than $20 \%$ of the studies. Other family ties, such as with siblings, nieces/ nephews, grandchildren, stepchildren, or inlaws were not heavily investigated.

In sum, researchers' investigations in these journals tended to focus on the social arena occupied by younger adults. These findings introduce questions about why relationship scholars focus on specific age groups and specific relationships.

\section{Study 2: Beliefs About the Importance of Relationships}

Study 2 provides a follow-up to Study 1 by examining beliefs about the importance of different social ties. Relationship scholars may study romantic, spousal, and childrearing ties due to their beliefs that these ties are the most important ones. Study 2 examined two aspects of beliefs about social ties: (a) the personal importance of these ties to individuals from different backgrounds, and (b) the importance of these ties to adults of different ages.

Scholars who study relationships may share certain traits that influence the value they place on specific relationships, traits that include their age, their high education level, and factors that attracted them to study relationships or information they acquired through their studies of relationships. Most scholars who publish research are actively involved in the work world, an arena that encompasses young or middle aged adults. Given that adults of different ages have different types of relationships, the limited age range of these scholars may contribute to biases. Likewise, scholars who publish research tend to have, or to be working toward obtaining, advanced degrees. Class differences in the value placed on autonomy and independence versus strong ties to family and friends are well documented (Hughes \& Perry-Jenkins, 1996; Kohn, 1977; Roschelle, 1997; Rubin, 1976). Finally, relationship scholars differ from other individuals with advanced degrees by virtue of their interest in and their study of the social world. Study 2 examined whether these factors were associated with beliefs about the importance of various social ties.

\section{Study 2 Methods}

Study $2(N=186)$ included three subsamples: scholars who study relationships, individuals with advanced degrees in other fields, and individuals with less education. These subsamples allowed comparisons of the influence of age, education, and interest in studying social ties on beliefs about the importance of various relationships. To obtain the subsample of relationship scholars, we randomly selected 200 researchers who had published the studies on social ties described in Study 1. We contacted these researchers via electronic mail and asked them to participate in a study of the importance of social ties $(n=71)$. We refer to this group as relationship scholars. The second subsample (the well-educated) included individuals matched to the relationship scholars with regard to educational level, but holding advanced degrees in other fields, such 
as science, humanities, business, law, or medicine. Participants in this subsample $(n=57)$ were contacted through colleagues in other fields (who recruited their colleagues), searches on university web pages (e.g., a scholar in an unrelated field from the same institution as a relationship scholar selected for participation), and word of mouth. The third subsample included individuals who had a maximum of a college degree, with $70 \%$ of this subsample having a high school degree or less education. This subsample $(n=58)$ was recruited through community groups, churches, workplaces, and word of mouth.

The mean ages of the three subsamples did not differ $($ mean $=43$ years, $S D=11.91)$. The well-educated and less-educated subsamples included larger age ranges (range 20 to 81 years) than the relationship scholars subsample (range 27 to 60 years). Men and women were equally represented in the relationship scholars and advanced degree subsamples, but more women than men participated in the less-educated group. Information about ethnicity is not available.

\section{Procedure}

Participants completed questionnaires in which they rated the applicability of specific relationships to themselves and to adults of different ages. They then rated the importance of these relationships to themselves and to adults of different ages. They also provided information about their own age, gender, and educational level. Participants had the option of completing the questionnaire via electronic mail or through a hard copy and return mail.

We generated a list of 36 relationships from the empirical literature described in Study 1 and from a study of close relationships involving a sample ages 13 to 99 years (Fingerman \& Birditt, in press). This list is found in Table 4. First, participants provided ratings of each relationship for themselves. They indicated whether they had such a relationship. If so, they then indicated how much they valued the relationship using a scale of 1 to $10(1=$ not at all important, $10=$ most important $)$.

Next, participants rated their beliefs about these relationships for adults in five age groups: young adulthood (ages 18 to 25 years), young middle adulthood (ages 30 to 39), middle adulthood (ages 45 to 55), young old age (ages 60 to 70), and old-old age (over age 80). These age ranges were selected to be discrete enough to encompass a specific age category yet broad enough to represent a range of adulthood. Participants indicated whether they thought adults in each age group had that relationship (e.g., they might check "not applicable" for grandparents for adults over the age of 80). If participants indicated the relationship applied, they also rated how important they believed the relationship was to adults in that age group using the same scale of 1 to $10(1=$ not at all important, $10=$ most important).

Asking participants to rate 36 relationships for self and five age groups could introduce response sets. Instead, we randomly selected 8 relationships from the larger list, generating a unique questionnaire for each participant (see Rossi \& Rossi, 1990, for a description of this approach). At least 10 participants in each subsample (with an average total of 41 participants) rated each relationship, providing sufficient sample size to estimate the ANCOVA analyses described below (Brent, Mirielli, \& Thompson, 1993). This approach allows independence of ratings for each type of relationship because a unique subset of the total sample rated each relationship.

Pilot tests including individuals from the three sampling groups revealed differences in their interpretations of questions about relationships. The final questionnaires reflected the preferences of individuals who do not study relationships. In the pilot tests, relationship scholars argued that relationships that do not widely exist in the population should be excluded (e.g., grandparents in old-old age), but individuals in the other two subsamples pointed out that such ties could be meaningful (e.g., social partners who have died may remain psychologically important). Non-social scientists also preferred a rating scale with the anchor $10=$ most important $($ rather than $10=$ excellent or another descriptive adjective); they believed that this anchor could apply to more than one relationship, despite the implication of a single tie in the word "most." 
Table 4. Personal applicability and importance of each social tie to participants

\begin{tabular}{|c|c|c|c|}
\hline Relationship & $\begin{array}{l}\text { Proportion considers } \\
\text { tie applicable }\end{array}$ & $\begin{array}{l}\text { Point biserial correlations } \\
\text { of applicability with age }\end{array}$ & $\begin{array}{l}\text { Average rating of } \\
\text { importance } \\
(\text { scale } 1 \text { to } 10)^{\mathrm{a}}\end{array}$ \\
\hline \multicolumn{4}{|l|}{ Romantic and family ties } \\
\hline Spouse & .75 & .12 & 9.61 \\
\hline Romantic partner & .92 & $-.60 * *$ & 9.18 \\
\hline Daughter & .54 & $.36^{*}$ & 9.22 \\
\hline Son & .44 & $.42 *$ & 9.13 \\
\hline Mother & .95 & $-.37 *$ & 8.03 \\
\hline Father & .90 & -.17 & 8.39 \\
\hline Brother & .74 & -.14 & 7.35 \\
\hline Sister & .76 & .12 & 7.44 \\
\hline Grandchild & .30 & $.32 *$ & 7.50 \\
\hline Grandmother & .48 & -.23 & 6.43 \\
\hline Grandfather & .52 & -.26 & 6.55 \\
\hline Daughter-in-law & .24 & $.34 *$ & 7.70 \\
\hline Son-in-law & .12 & $.58 * *$ & 7.50 \\
\hline Niece or nephew & .85 & .10 & 6.22 \\
\hline Aunt or uncle & .92 & $-.51 * *$ & 5.29 \\
\hline Cousin & .95 & .06 & 4.92 \\
\hline Mother-in-law & .73 & -.12 & 5.89 \\
\hline Father-in-law & .52 & -.05 & 5.92 \\
\hline Sister/Brother-in-law & .80 & .16 & 5.43 \\
\hline Stepmother & .20 & -.17 & 6.17 \\
\hline Stepfather & .17 & -.12 & 7.20 \\
\hline Stepchild & .25 & .15 & 7.11 \\
\hline Ex-boyfriend/girlfriend & .75 & $-.38^{*}$ & 2.59 \\
\hline Ex-spouse & .27 & -.05 & 2.50 \\
\hline \multicolumn{4}{|l|}{ Friendship ties } \\
\hline Friend & 1.00 & - & 7.82 \\
\hline Best friend & 1.00 & - & 7.94 \\
\hline \multicolumn{4}{|l|}{ Peripheral ties } \\
\hline Acquaintance & 1.00 & - & 4.51 \\
\hline Boss & .79 & -.22 & 5.63 \\
\hline Co-worker & .90 & $-.50 * *$ & 6.23 \\
\hline Church member & .59 & $.31 *$ & 5.14 \\
\hline Minister & .93 & .14 & 5.43 \\
\hline Teacher & .74 & -.13 & 7.14 \\
\hline Neighbor & 1.00 & $.31 *$ & 4.38 \\
\hline Schoolmate & .98 & -.15 & 6.27 \\
\hline Roommate & .17 & $-.33 *$ & 6.43 \\
\hline Club/Team Member & .66 & -.14 & 5.38 \\
\hline
\end{tabular}

${ }^{\mathrm{a}} 1=$ not at all important, $10=$ most important.

$* p<.01, * * p<.005$. 


\section{Results of Study 2}

We looked at how participants of different ages and from different subsamples rated relationships using the following strategy. First, we examined participants' indications of the applicability of the tie $(1=$ rated the relationship as applicable, $0=$ rated the relationship as not applicable). Because these ratings were dichotomous, we used point biserial correlations to examine associations between participants' ages and their ratings of the applicability of the tie. We used chi-square tests to look at subsample differences (relationship scholars, advanced degree, less education) in the applicability of each relationship. To examine differences in the importance of each relationship (rated on a scale of 1 to 10), we estimated ANCOVAs, with subsample as an independent variable and age of participant as a covariate. Participants' ratings of relationships for themselves are considered first, followed by their ratings of ties for adults of different ages.

\section{Personal importance of relationships}

The first column of Table 4 shows the proportions of participants who indicated that they themselves had a given relationship $(1=$ rated the relationship as applicable, $0=$ rated the relationship as not applicable). Point biserial correlations between participants' ages and the applicability of each social tie can be seen in the second column of Table 4. In general, older participants were more likely to have relationships with younger generations (e.g., son, daughter, grandchild) and younger participants to have relationships with older generations (e.g., mother, aunt, grandparents). Older participants were also likely to indicate that church members and neighbors were applicable. Chi-square tests examining differences between the three subsamples (relationship scholars, advanced degree, less education) with regard to the applicability of each relationship revealed few differences, so those tests are not shown here.

Next, we examined ratings of the personal importance of each social tie (rated on a scale of 1 to 10) for participants who considered the tie applicable. Mean ratings of the personal importance of each relationship are indicated in the third column of Table 4. At a descriptive level, participants in all three subsamples gave the highest mean ratings ( 9 points or higher) to their spouses, children, and romantic partners. Participants also rated other close family relationships and friendships as having considerable importance (mean 7 to 8.5). Distant family members and peripheral ties were rated as moderately important (mean 4 to 6 ), with the exception of teachers (who were rated higher).

To examine differences in the personal importance of social ties associated with participants' ages and subsample membership, one-way ANCOVAs were estimated. Rating of the personal importance of each relationship on a scale of 1 to 10 was the dependent variable, the subsample was the independent variable (relationship scholars, advanced degree, less educated), and age of participant the covariate. Based on power analyses (Brent et al., 1993), ANCOVAs were only estimated if at least 30 participants (with at least 8 individuals in each subsample) considered the relationship applicable. $F$ tests from significant ANCOVAs are given in Table 5. There were few effects for participants' ages on ratings of ties, but there were differences between subsamples in the ratings. Tukey's post hoc tests revealed that the biggest differences fell between the ratings by relationship scholars' and those by the lesseducated individuals, with the less-educated individuals valuing certain relationships more than relationship scholars did. Ratings by participants with advanced degrees in other fields fell between these two subsamples.

In sum, participants of different ages reported having different types of relationships. For participants who had each relationship, however, participants' ages were not associated with their value for the relationship. Rather, subsample membership was associated with the value participants placed on relationships, with less-educated adults valuing several relationships more than relationship scholars did.

\section{Value of relationships to adults of different ages}

Analyses next focused on participants' beliefs about the value of different relationships to 
Table 5. ANCOVAs examining subsample and age differences in the personal importance of each relationship

\begin{tabular}{|c|c|c|c|}
\hline Relationship & $\begin{array}{c}F \text { Tests for } \\
\text { participant age }\end{array}$ & $\begin{array}{c}F \text { Tests for } \\
\text { subsample differences }\end{array}$ & $\begin{array}{c}\text { Posthoc test of } \\
\text { subsample differences }\end{array}$ \\
\hline \multicolumn{4}{|l|}{ Family and romantic ties } \\
\hline Spouse & NS & NS & \\
\hline Romantic partner & NS & NS & \\
\hline Daughter & NS & NS & \\
\hline Son & - & - & \\
\hline Mother & NS & NS & \\
\hline Father & NS & $6.88 * *$ & $\mathrm{~L}>\mathrm{A} \& \mathrm{~S}$ \\
\hline Brother & $5.24 *$ & $7.23 * *$ & $\mathrm{~L}>\mathrm{S}$ \\
\hline Sister & NS & NS & \\
\hline Grandchild & - & - & \\
\hline Grandmother & - & - & \\
\hline Grandfather & - & - & \\
\hline Daughter-in-law & - & - & \\
\hline Son-in-law & - & - & \\
\hline Niece or nephew & NS & NS & \\
\hline Aunt or Uncle & NS & NS & \\
\hline Cousin & NS & NS & \\
\hline Mother-in-law & NS & $5.49 *$ & $\mathrm{~L}>\mathrm{A} \& \mathrm{~S}$ \\
\hline Father-in-law & - & - & \\
\hline Sister/Brother-in-law & NS & $3.52 *$ & $\mathrm{~L}>\mathrm{S}$ \\
\hline Stepmother & - & - & \\
\hline Stepfather & - & - & \\
\hline Stepchild & - & - & \\
\hline Ex-boyfriend/girlfriend & - & - & \\
\hline Ex-spouse & - & - & \\
\hline \multicolumn{4}{|l|}{ Friendship ties } \\
\hline Friend & $7.73 *$ & NS & \\
\hline Best friend & NS & NS & \\
\hline \multicolumn{4}{|l|}{ Peripheral ties } \\
\hline Acquaintance & NS & 6.20 & $\mathrm{~L} \& \mathrm{~A}>\mathrm{S}$ \\
\hline Boss & NS & $5.92 *$ & $\mathrm{~L}>\mathrm{S}$ \\
\hline Co-worker & NS & NS & \\
\hline Church member & $4.60 *$ & NS & \\
\hline Minister & NS & $5.50 *$ & $\mathrm{~L}>\mathrm{A}>\mathrm{S}$ \\
\hline Teacher & NS & NS & \\
\hline Neighbor & $8.31 *$ & 4.62 & $\mathrm{~L}>\mathrm{S}$ \\
\hline Schoolmate & NS & NS & \\
\hline Roommate & - & - & \\
\hline Club/Team Member & NS & NS & \\
\hline
\end{tabular}

$\mathrm{S}=$ relationship scholar subsample, $\mathrm{A}=$ advanced degree subsample, $\mathrm{L}=$ less-educated subsample. $\mathrm{NS}=F$ test to significant $* p<.01, * * p<.005$. 
adults of different ages. First, point biserial correlations were estimated to examine the associations between participants' own ages and their beliefs about the applicability of each relationship to adults in the five age groups (adults ages 18 to 25 years, 30 to 39,45 to 55 , etc.). Few of these correlations were significant. Chi-squares tests comparing the three subsamples on ratings of the applicability of each tie $(1=$ applicable, $0=$ not applicable $)$ for adults in each age group also revealed few differences. These analyses are not presented. For example, most participants agreed that grandchildren were not applicable to 18 - to 25 -year-olds, but that romantic partners were applicable for this age group.

Then we considered participants' ratings of the importance of relationships for adults in five age groups (adults aged 18 to 25 years, 30 to 39,45 to 55 , etc.). The ratings of the five age groups were not independent. Therefore, we estimated repeated measures ANCOVAs with ratings of the importance of each relationship as the dependent variable, the five age groups rated as the repeated measure, subsample (relationship scholars, advanced degree, less educated) as the independent variable, and age of participant as a covariate. By examining the repeated measure component, we could ascertain whether participants thought adults in different age groups valued relationships differently. When a majority of participants rated a relationship as not applicable to a particular age group (e.g., grandchildren to adults aged 18 to 25 years, boss for adults over age 60), repeated ratings for only the three or four relevant age groups were examined. Analyses were not estimated for roommates because a majority of relationship scholars considered roommates irrelevant for all age groups except the 18- to 25-year-olds (although the other two subsamples considered roommates applicable to a broader age range).

Significant findings for the repeated ratings and subsample differences from the ANCOVAs are found in Table 6. Participants' own ages were generally not associated with their beliefs about the importance of relationships to adults of different ages. There were few effects for age of participant, within subject $\times$ group interactions, or within subject $\times$ age interactions.
These findings are not presented. Column 1 of Table 6 contains findings for the repeated factor testing whether participants rated relationships as having different value to adults of different ages. Column 2 contains the direction of this effect when participants rated relationships differently for adults of different ages. In the table, comparisons are presented as follows: Linear main effects for age (e.g., younger better or worse than older adults) are represented by $\mathrm{Y}$ (younger) or $\mathrm{O}$ (older); interaction effects (e.g., middle-aged adults better or worse than younger or older adults) are represented by $\mathrm{M}$ (middle-aged) in comparison with $\mathrm{Y}$ and $\mathrm{O}$. Participants rated the importance of many relationships differently for adults of different ages. For example, participants rated mothers as being more important for younger adults than older adults. Column 3 contains the effects for subsample (relationship scholars, advanced degree, less education) differences in the ratings. Column 4 contains the directions of those effects based on Tukey's post hoc tests. Again, less-educated individuals rated several relationships as more important than did relationship scholars; individuals possessing advanced degrees in other fields fell between these two subsamples.

We wondered whether participants' personal value for a given relationship might influence their beliefs about other people. Post hoc, we estimated Pearson's correlations between participants' ratings of the personal importance of each relationship and their ratings of the importance of these relationships to adults of different ages. In general, participants' personal ratings of the importance of social ties correlated significantly with their ratings of the importance of these ties for adults aged 30 to 39 years and adults aged 45 to 55 . There were few significant correlations, however, between participants' ratings of the personal importance of ties and their ratings for other adults when it came to family ties (e.g., spouse, brother, daughter, mother-in-law).

\section{Study 2 Discussion}

This study examined the personal importance of and beliefs about the importance of social ties to adults of different ages. We were 
Table 6. Significant findings from repeated measures ANCOVAs examining participants' ratings of the importance of each relationship to adults of different ages

\begin{tabular}{|c|c|c|c|c|}
\hline Relationship & $\begin{array}{l}\text { Within-subject } \\
\text { repeated factor } \\
\quad F \text { and } \\
\text { significance }\end{array}$ & $\begin{array}{l}\text { Direction of } \\
\text { effect for } \\
\text { ratings of } \\
\text { age groups }\end{array}$ & $\begin{array}{l}\text { Between-subjects } \\
\text { subsample } \\
\text { differences } F \\
\text { and significance }\end{array}$ & $\begin{array}{l}\text { Post hoc } \\
\text { between } \\
\text { group tests }\end{array}$ \\
\hline \multicolumn{5}{|l|}{ Romantic and family ties } \\
\hline Spouse & - & & - & \\
\hline Romantic partner & - & & - & \\
\hline Daughter & - & & - & \\
\hline Son & - & & - & \\
\hline Mother & $5.85^{* * *}$ & $\mathrm{Y}>\mathrm{O}$ & - & \\
\hline Father & - & & - & \\
\hline Brother & - & & - & \\
\hline Sister & - & & - & \\
\hline Grandchild $^{\mathrm{a}}$ & $6.48 * * *$ & $\mathrm{O}>\mathrm{Y}$ & $6.59 * *$ & $\mathrm{~L}>\mathrm{S}$ \\
\hline Grandmother $^{\mathrm{a}}$ & $5.85^{* * *}$ & $\mathrm{Y}>\mathrm{O}$ & $4.47 * *$ & $L>A \& S$ \\
\hline Grandfather $^{\mathrm{a}}$ & $10.02 * * *$ & $\mathrm{Y}>\mathrm{O}$ & - & \\
\hline Daughter-in-law ${ }^{\mathrm{a}}$ & 5.81 & $\mathrm{O}>\mathrm{Y}$ & - & \\
\hline Son-in-law ${ }^{\mathrm{a}}$ & $7.03 * * *$ & $\mathrm{O}>\mathrm{Y}$ & $7.05^{* *}$ & $\mathrm{~L}>\mathrm{S}$ \\
\hline Niece or nephew & - & & - & \\
\hline Aunt or uncle ${ }^{b}$ & - & & - & \\
\hline Cousin & - & & $3.69^{*}$ & $\mathrm{~L} \& \mathrm{~A}>\mathrm{S}$ \\
\hline Mother-in-law ${ }^{\mathrm{a}}$ & $2.37^{*}$ & $\mathrm{Y}>\mathrm{O}$ & - & \\
\hline Father-in-law ${ }^{\mathrm{a}}$ & - & & - & \\
\hline Sister/Brother-in-law & - & & $6.78^{* *}$ & $\mathrm{~L}>\mathrm{S}$ \\
\hline Stepmother ${ }^{\mathrm{a}}$ & - & & - & \\
\hline Stepfather ${ }^{\mathrm{a}}$ & $2.67 *$ & $\mathrm{O}>\mathrm{Y}$ & - & \\
\hline Stepchild & - & & - & \\
\hline Ex-boyfriend/girlfriend & $8.80 * * *$ & $\mathrm{Y}>\mathrm{O}$ & - & \\
\hline Ex-spouse & $5.76^{* *}$ & $\mathrm{M}>\mathrm{Y} \& \mathrm{O}$ & - & \\
\hline \multicolumn{5}{|l|}{ Friendship ties } \\
\hline Friend & - & & - & \\
\hline Best friend & $2.39 *$ & $\mathrm{Y}>\mathrm{O}$ & - & \\
\hline \multicolumn{5}{|l|}{ Peripheral ties } \\
\hline Acquaintance & - & $7.17 * * *$ & $7.17 * * *$ & $\mathrm{~L} \& \mathrm{~A}>\mathrm{S}$ \\
\hline Boss $^{a}$ & $4.42 * *$ & $\mathrm{M}>\mathrm{Y} \& \mathrm{O}$ & $3.75^{*}$ & $\mathrm{~L}>\mathrm{A} \& \mathrm{~S}$ \\
\hline Co-worker ${ }^{\mathrm{a}}$ & $5.87 * *$ & $\mathrm{Y}>\mathrm{O}$ & - & \\
\hline Church member & $3.04 *$ & $\mathrm{O}>\mathrm{Y}$ & $9.13 * * *$ & $\mathrm{~L}>\mathrm{A}>\mathrm{S}$ \\
\hline Minister & $13.64 * * *$ & $\mathrm{O}>\mathrm{Y}$ & $3.39 *$ & $\mathrm{~L}>\mathrm{A}>\mathrm{S}$ \\
\hline Teacher & - & & - & \\
\hline Neighbor & $5.45 * * *$ & $\mathrm{O}>\mathrm{Y}$ & $3.37 *$ & $L>A \& S$ \\
\hline Schoolmate & $3.32 *$ & $\mathrm{Y}>\mathrm{O}$ & - & \\
\hline Club or team member & $2.78^{*}$ & $\mathrm{Y}>\mathrm{O}$ & - & \\
\hline
\end{tabular}

Note. $\mathrm{Y}=$ younger adults, $\mathrm{M}=$ middle-aged adults, $\mathrm{O}=$ older adults.

$\mathrm{S}=$ relationship scholar subsample, $\mathrm{A}=$ advanced degree subsample, $\mathrm{L}=$ less-educated subsample ${ }^{\mathrm{a}}$ Analyses estimated on three age groups rated as relevant.

${ }^{\mathrm{b}}$ Analyses estimated on four age groups rated as relevant.

$* p<.05, * * p<.01, * * * p<.001$. 
interested in whether age, educational level, and interest in social ties contribute to the value individuals place on different social ties. We considered both the personal value people placed on these social ties and their beliefs about how much adults of different ages value these ties.

Participants of different ages indicated that they have different social partners. When participants indicated that a social tie was not personally applicable, lack of applicability was associated with age. Younger participants were less likely to have grandchildren or childrenin-law; older participants were less likely to have mothers or aunts or uncles. Among participants who did report having particular relationships, age was not associated with the importance they placed on the tie. Participants indicated that close family ties (e.g., spouse and children) and romantic partners were very important to them personally, as were parents and friends. Yet, participants' background seemed to influence the importance they placed on certain ties; less-educated individuals rated some relationships as more important than relationship scholars did.

In general, there was consensus on the applicability and importance of ties for adults of different ages. Regardless of their own ages or background, participants considered ties to older generations (e.g., parent, grandparent) more applicable and important for younger adults, and ties to younger generations (e.g., grandchild, child) more applicable and important for older adults. Participants also rated romantic ties and many peripheral ties as more important to younger adults than older adults. Church members and neighbors, however, were considered more important to older adults than to younger adults.

Despite this general consensus, participants' backgrounds influenced their beliefs about the importance of social ties. Lesseducated adults rated ties to grandparents and grandchildren, cousins, and in-laws as highly important to adults of different ages, whereas relationship scholars did not. Relationship scholars also generally rated peripheral ties as less important than did the less-educated participants. Ratings of relationships observed here might be associated with educational disparities and the value well-educated adults place on autonomy (e.g., Hughes \& PerryJenkins, 1996; Kohn, 1977). Yet participants with advanced degrees in other fields provided ratings that fell between the other two subsamples. Therefore, factors associated with the study of relationships may also influence these researchers' beliefs about the importance of different relationships.

In addition, post hoc tests suggested that participants' personal value for relationships were associated with their beliefs about the value of those relationships to other adults aged 30 to 55 years (with the exception of family ties, which were widely valued by most participants). Although the samples included a wide age range, the majority of participants fell between the ages of 30 and 60. Future studies should examine how relationship scholars' ages and personal value for relationships influence the literature on personal and family relationships.

\section{General Discussion}

Research pertaining to family and personal relationships appears to involve systematic age biases. These age biases have complex implications for the types of relationships studied. Further, these biases seem to reflect a combination of factors including the convenience of sampling young adults, the high education levels of relationship researchers, and researchers' beliefs about the importance of these relationships.

\section{Age biases}

An analogy for the current state of research on adults' social ties might be developmental psychologists who focus only on 4-year-olds' cognition using Piagetian tasks and conclude that children under 18 do not understand that water poured from a pitcher to a glass retains its volume. It is not possible to generalize across adulthood from studies of young adults. The social worlds of younger and older adults share certain commonalties but are also distinct in many respects, including the availability of different social partners, the desired quantity of social ties, and the value 
placed on specific relationships (Antonucci, 2001; Carstensen, 1995).

Biases in the literature were found to extend beyond simple favoritism toward younger adults; age itself was ignored as a variable in approximately one third of studies examined in Study 1. This oversight does not appear to reflect beliefs that age is not important. Rather, Study 2 revealed that adults from different backgrounds concur that adults of different ages have distinct relationships and place different value on those relationships. Therefore, other factors, such as feasibility of conducting research with adults of different ages, may influence the nature of research.

\section{Relationship biases and age of samples}

We had expected to find that researchers placed the greatest emphasis on the spousal, romantic, and childrearing ties that are of importance to young adults, in keeping with sampling biases. Findings from Study 1 confirmed this expectation. Further, in Study 2, participants showed a strong consensus that relationships with spouses and romantic partners are of great importance to adults of all ages. Therefore, it would be overstating the case to suggest that relationships to romantic partners and spouses do not warrant considerable research attention.

At the same time, many other social ties of importance have been all but ignored in the literature. For example, participants in Study 2 agreed that older adults greatly value childrenin-law and grandchildren. Yet relatively few empirical studies have examined these relationships. Furthermore, peripheral ties appeared in only $5 \%$ of the studies we examined. Participants in Study 2 rated these relationships as at least moderately important to adults of different ages. Moreover, participants in Study 2 believed that certain peripheral ties (e.g., church ties, neighbors) are more important to older adults than to younger adults. Clearly, peripheral ties are not simply the purview of younger adults.

In sum, although marital and childrearing relationships are clearly important, other relationships receive so little research attention that there is not sufficient theory or findings to understand their importance and functions. Relationship scholars and non-social scientists concurred that adults of different ages value different social ties. Furthermore, participants felt that many relationships were of greater importance to older adults than to younger adults.

\section{Factors underlying observed biases}

Findings from Study 2 suggest that biases found in the research literature stem from a combination of factors. The observed differences in the importance ascribed to relationships are not due solely to education. These differences also appear to reflect distinct beliefs held by relationships scholars.

We started this paper with the idea that researchers may conduct research on social ties that are easy to investigate. The frequent use of college-student samples suggests convenience is a factor in some research. The imperatives of publishing research papers in high volume may lead researchers to rely on readily available participants (college students) or on existing secondary data sets (that do not include older adults). Further, it may be difficult to recruit older adults into studies of personal relationships. Adults in their 50s and 60s may have little spare time; at this life stage, obligations to family, work, and community are high and health problems emerge (Fingerman, Nussbaum, \& Burditt, in press). By the age of 80 , most adults suffer from illness, sensory loss, cognitive impairments, or frailty (Johnson \& Barer, 1997). In sum, high publication demands and difficulties of researching older adults contribute to the current state of the literature.

\section{Limitations and suggestions for future research}

Of course, the studies presented here also suffer from limitations. We did not include the full array of journal articles on relationships that were published during the six-year period, though we did focus on journals likely to have a large impact on family and social relationship research. It is unlikely that a large number of articles on these topics are published elsewhere. A cursory examination 
of journals addressing specific age groups (e.g., Psychology and Aging, Developmental Psychology) and of specialty journals (e.g., Journal of Divorce and Remarriage) revealed few studies examining older adults' relationships.

Finally, we too plead guilty to sampling for convenience. The subsamples in Study 2 included proportional representation of gender, but the ethnic compositions of the samples are unknown. Future research might pursue age differences in social ties as a function of gender, ethnicity, and other such variables. Furthermore, we did not include random selections of scholars who publish articles on social ties (nearly two thirds of relationship scholars contacted did not complete the survey). Nor were the individuals with advanced degrees or less education randomly selected; our colleagues in other departments selected some of these individuals. Indeed, biases in the subsamples may

\section{References}

Adams, R. G. (1988, November). A gender-informed approach to friendship in late life. In T. M. Calasanti (Chair), Incorporating gender into theory and research on aging. Symposium conducted at the 41st annual meeting of the Gerontological Society of America, San Francisco.

Agnew, C. R., Van Lange, P. A. M., \& Rusbult, C. E. Langston, C. A. (1998). Cognitive interdependence: Commitment and the mental representation of close relationships. Journal of Personality and Social Psychology, 74, 939-954.

Antonucci, T. C (2001). Social relations: An examination of social networks, social support, and sense of control. In J. E. Birren \& K. W. Schaie (Eds.), Handbook of the psychology of aging (5th ed., pp. 427-453). San Diego, CA: Academic Press.

Antonucci, T. C., \& Akiyama, H. (1987). Social networks in adult life and a preliminary examination of the convoy model. Journal of Gerontology, 42, 519-527.

Becerra, R. M. (1988). The Mexican American family. In C. H. Mindel, R. W. Habenstein, \& R. Wright (Eds.), Ethnic families in America (pp. 141-159). Englewood Cliffs, NJ: Prentice-Hall.

Bedford, V. H., \& Blieszner, R. (1997). Personal relationships in later life families. In S. Duck (Ed.), Handbook of personal relationships (2nd ed.). New York: Wiley.

Blieszner, R., \& Adams, R. G. (1992). Adult friendship. Thousand Oaks, CA: Sage.

Brent, E. E., Mirielli, E. J., \& Thompson, A. (1993). EXSAMPLE: An expert system for determining sample size. Version 3 [computer software]. Colombia, MO: Idea Works.

Cantor, M. H. (1979). Neighbors and friends: An over- account for some of the differences observed in Study 2.

In summary, many studies in family science and personal relationship journals have ignored the importance of age as a variable in adults' social worlds. Adults of different ages value different types of family and peripheral ties. Moreover, adults of all ages place a high value on friendships and extended family ties that receive little coverage in the research literature. To more accurately represent adults' social worlds, researchers need to be aware of ageism and of the value they themselves place on specific relationships. Adults over the age of 65 constitute the fastest growing segment of the population in the United States today and their social ties warrant increased attention in the research literature. We have garnered considerable understanding of the area around the streetlight, but it is time to canvas the rest of the block.

looked resource in the informal support system. Research on Aging, 1, 434-463.

Carstensen, L. L. (1995). Evidence for a life-span theory of socioemotional selectivity. Current Directions in Psychological Science, 4, 151-155.

Doherty, W. J., Boss, P. G., LaRossa, R., Schumm, W. R., \& Steinmetz, S. K. (1993). Family theories and methods: A contextual approach. In P. G. Boss, W. J. Doherty, R. LaRossa, W. R. Schumm, \& S. K. Steinmetz (Eds.), Sourcebook of family theories and methods: A contextual approach (pp. 3-30). New York: Plenum Press.

Fingerman, K. L. (2001). Aging mothers and their adult daughters: A study in mixed emotions. New York: Springer.

Fingerman, K. L. (in press). The consequential stranger: Peripheral social ties across the lifespan. To appear in F. R. Lang \& K. L. Fingerman (Eds.), Growing together: Personal relationships across the lifespan. New York: Cambridge University Press.

Fingerman, K. L., \& Bermann, E. (2000). Applications of family systems theory to the study of adulthood. International Journal of Aging and Human Development, 51, 5-29.

Fingerman, K. L., \& Birditt, K. S. (in press). Do age differences in close and problematic family ties reflect the pool of available relatives? Journals of Gerontology: Psychological Sciences.

Fingerman, K. L., \& Griffiths, P. C. (1999). Season's greetings: Adults' social contact at the holiday season. Psychology and Aging, 14, 192-205.

Fingerman, K. L., Nussbaum, J., \& Burditt, K. S. (in press). Keeping all five balls in the air: Juggling family communication at midlife. In A. L. Vangelisti (Ed.), 
Handbook of family communication. Mahwah, NJ: Erlbaum.

Franklin, J. H. (1997). African American families: A historical note. In H. P. McAdoo (Ed.), Black families (3rd ed., pp. 5-8). Thousand Oaks, CA: Sage.

Gaines, S. O. (1995). Relationships between members of members of cultural minorities. In J. T. Wood \& S. Duck (Eds.), Under-studied relationships: Off the beaten track (pp. 51-88). Thousand Oaks, CA: Sage.

Gurung, R. A. R., Sarason, B. R., \& Sarason, I. G. (1997). Personal characteristics, relationship quality, and social support perceptions and behavior in young adult romantic relationships. Personal Relationships, 4, 319-339.

Hughes, R., \& Perry-Jenkins, M. (1996). Social class issues in family life education. Family Relations, 45, $175-182$.

Ingersoll-Dayton, B., \& Talbott, M. M. (1992). Assessments of social support exchanges: Cognitions of the old-old. International Journal of Aging and Human Development, 35, 125-143.

Johnson, C., \& Barer, B. (1997). Life beyond 85 years: The aura of survivorship. New York: Springer.

Kohn, M. L. (1977). Class and conformity: A study in values. Homewood, IL: Dorsey Press.

Krause, N. (1995). Religiosity and self-esteem among older adults. Journals of Gerontology, 50B, P236-P246.

Levitt, M. J., Weber, R. A., \& Guacci, N. (1993). Convoys of social support: An intergenerational analysis. Psychology and Aging, 8, 323-326.

Leyendecker, B., \& Lamb, M. E. (1999). Latino families. In M. E. Lamb (Ed.), Parenting and child development in "nontraditional" families (pp. 247-262). Mahwah, NJ: Erlbaum.

McGoldrick, M. (1993). Ethnicity, cultural diversity, and normality. In F. Walsh (Ed.), Normal family processes (2nd ed., pp. 331-360). New York: Guilford Press.

Morgan, D. L. (1989). Adjusting to widowhood. The Gerontologist, 29, 101-107.

National Center for Health Statistics. (2001). Health, United States. Retrieved March 1, 2002, from http:// www.cdc.gov/nchs/products/pubs/pubd/hus/tables/ 2001/olhus057.pdf
Parsons, T. (1949). The social structure of the family. In R. Anshen (Ed.), The family: Its function and destiny (pp. 173-201). New York: Harper \& Row.

Parsons, T. (1960). Structure and process in modern societies. Glencoe, IL: The Free Press.

Roschelle, A. R. (1997). No more kin: Exploring race, class, and gender in family networks. Thousand Oaks, CA: Sage.

Rossi, A. S., \& Rossi, P. H. (1990). Of human bonding: Parent-child relations across the life course. New York: Aldine de Gruyter.

Rubin, L. B. (1976). Worlds of pain: Life in the working-class family. New York: Basic Books.

Sanchez-Ayendez, M. (1988). The Puerto Rican American family. In C. H. Mindel, R. W. Habenstein, \& R. Wright (Eds.), Ethnic families in America (pp. 173-198). Englewood Cliffs, NJ: Prentice-Hall.

Spitze, G., \& Miner, S. (1992). Gender differences in adult-child contact among Black elderly parents. The Gerontologist, 32, 213-217.

Sudarkasa, N. (1997) African American families and family values. In H. P. McAdoo (Ed.), Black families (3rd ed., pp. 9-40). Thousand Oaks, CA: Sage.

Taylor, R. J., Jackson, J. S., \& Chatters, L. M. (1997). Family life in Black America. Thousands Oaks, CA: Sage.

Troll, L. E. (1996). Modified-extended families over time: Discontinuity in parts, continuity in wholes. In V. Bengtson (Ed.), Adulthood and aging: Research on continuities and discontinuities (pp. 246-268). New York: Springer.

U.S. Census Bureau (2000). Census of population: General population characteristics. Population Estimates Program. Washington, DC: Government Printing Office.

Widmer, E. D. (1999). Family contexts as cognitive networks: A structural approach of family relationships. Personal Relationships, 6, 487-503.

Wood, J. T., \& Duck, S. (1995). Off the beaten track: New shores for relationship research. In J. T. Wood \& S. Duck (Eds.), Under-studied relationships: Off the beaten track (pp. 1-21). Thousand Oaks, CA: Sage. 